\title{
Spatio-temporal dynamics of a Zostera noltii dominated community over a period of fluctuating salinity in a shallow lagoon, Southern France
}

\author{
A. Charpentier ${ }^{a,}{ }^{*}$, P. Grillas ${ }^{a}$, F. Lescuyer ${ }^{b}$, E. Coulet $^{b}$ and I. Auby ${ }^{c}$ \\ ${ }^{\mathrm{a} S}$ Station Biologique de la Tour du Valat, Le Sambuc, 13200 Arles, France \\ ${ }^{\mathrm{b}}$ SNPN, Réserve Nationale de Camargue, La Capelière, 13200 Arles, France \\ 'Laboratoire IFREMER DEL/AR, Quai du Commandant Silhouette, 33120 Arcachon, France \\ *: Corresponding author : A. Charpentier, email address : charpentier@tourduvalat.org
}

\begin{abstract}
:
The consequences of a sudden decrease in water salinity on a macrophyte community dominated by the marine species Zostera noltii were investigated in a shallow coastal lagoon (Southern France). The expected change in the community assemblage was a competitive displacement of $Z$. noltii by Potamogeton pectinatus and Ruppia cirrhosa. However, the results of an eight-year survey did not validate this hypothesis. Zostera noltii remained dominant after three years at low salinity (ca. 5) and then suddenly disappeared within one year. The decline of Z. noltii was not associated with an increase of other species. The maximum depth colonized by all species decreased, suggesting that light availability became a limiting factor for the aquatic vegetation. The high concentration in suspended sediments that was measured when salinity was low may result from the synergetic effects of low salinity that slowed down the settling of suspended sediments and the disappearance of $Z$. noltii meadow that trapped sediments and reduced wave energy. The progressive recovery of the $Z$. noltii meadow following the increase in water salinity was associated with an increase in depth limit of the other species. However, the two other angiosperms remained present at low frequency of occurrence and the two charophytes (Lamprothamnium papulosum and Chara galioides) declined over the study period.
\end{abstract}

A geo-referenced database was constructed to investigate the spatial variation in Zostera noltii cover in relation to depth, slope, wave exposure and sediment characteristics using logistic regressions. During the first years of re-colonization, when $Z$. noltii was restricted to the shallow borders of the lagoon with the highest slope values, the best explanatory variables were depth and slope. In the following years, depth and wave exposure were the most important factors determining the spatial distribution of $Z$. noltii.

Keywords: seagrass; mapping; salinity; turbidity; loss; recovery; lagoon; Mediterranean sea 


\section{Introduction}

The spatial distribution of submersed aquatic vegetation is controlled by a variety of abiotic factors and their interactions. The large majority of published studies focuses on light and parameters that modify its availability (e.g. depth, suspended solids, phytoplankton, epiphytes) which are generally considered as the first factors to take into consideration (Duarte, 1991; Koch, 2001). A growing number of recent studies have highlighted the role of physical parameters other than light to explain the spatial distribution of submersed vegetation such as slope, sediment characteristics, waves and current velocity (Koch, 2001 for references). A broad knowledge on the salinity range of most of aquatic macrophytes and on the effect of salinity on their growth, reproduction or germination is now also available. Several studies have described changes in the distribution of seagrass or fresh water macrophytes along spatial salinity gradients (e.g. Adams et al., 1992; Menéndez et al., 2002; Kentula and DeWitt, 2003). However, the effect of temporal variations in salinity on community dynamics remain poorly documented. The expected scenario following a change in water salinity is a successional dynamics characterised by the replacement of species according to their salinity tolerance known from classification and/or autecological studies. At least two reasons can explain the lack of available data to test this scenario. First, to collect such data requires having the opportunity to witness events of significant salinity fluctuation and then requires a survey of the vegetation over a long period of time. A further difficulty comes from the fact that the events generally documented are major changes of the environment that affect not only salinity but a combination of several physical parameters. As a consequence, the published studies on the effect of salinity fluctuations on community structure and dynamics highlighted the difficulty of separating the respective impact of different factors (e.g. Zieman et al., 1999), such as salinity and eutrophication (Bales et al., 1993), dissolved silicon (Kamermans et al., 1999), dredging (Quammen and Onuf, 1993), and disturbance (Fletcher and Fletcher, 1995).

In this study we investigated the consequences of a sudden decrease in water salinity on the plant community of the Vaccarès, a shallow coastal lagoon in Southern France. Since the 1980s a relatively high water salinity $(15-30)$ had allowed the development of a large meadow of the marine species Zostera noltii (Vaquer and Heurteaux, 1989). After two successive major river floods in winter 19931994 , we expected the salinity decrease (to less than 5 ) to be followed by a progressive replacement of $Z$. noltii by the salt-tolerant freshwater macrophyte Potamogeton pectinatus and Ruppia cirrhosa. This hypothesis was supported by 2 facts: First, a large mixed meadow composed of $P$. pectinatus and $R$. cirrhosa occupied the lagoon in the 60's and 70's while the water salinity fluctuated around 10 (Vaquer and Heurteaux, 1989). Second, these 2 species were present in the wetlands surrounding the lagoon and thus vegetative propagules or seeds were available via water or bird dispersion.

Furthermore, we investigated the role of physical parameters other than salinity to explain the spatial variation in cover of the dominant species, $Z$. noltii. The Vaccarès lagoon is a large and shallow lagoon rich in fine sediments and situated in an area which $40 \%$ of the time is subject to a strong, dominant wind oriented from N-NW (Heurteaux, 1970). We thus suspected the possible effect of parameters such as water depth, wave exposure, slopes and sediment characteristics on the spatial distribution of the aquatic vegetation.

The aim of this study was:

- to determine the effect of temporal variation in water salinity on the plant community dynamics (frequency of occurrence, depth limit and cover of the species).

- to identify the main abiotic factors that control the spatial distribution of the dominant species, $Z$. noltii.

\section{Methods}

\subsection{Study site}

The Vaccarès lagoon (surface area: $60 \mathrm{~km}^{2}$, depth up to $2.1 \mathrm{~m}$ ) collects drainage water from the Rhône delta and is indirectly connected to the Mediterranean Sea through another lagoon. During the winter 1993-94, a massive freshwater input due to two successive major floods of the Rhône river resulted in a substantial decrease in water salinity which dropped from 14 to 7 in two months. Due to 
heavy rainfall during the following years, water salinity further slowly decreased until 1997, when it reached values of 4 . Salinity then progressively increased until 2001 to reach values close to the preflood values (ca. 14).

\subsection{Vegetation survey}

The systematic survey of the aquatic vegetation started in 1996. However fragmentary data existing on the meadow before the flood (1993) and for the two following years (1994 and 1995) is also presented in this paper.

\section{3-1995:}

In the summer 1993, 1994 and 1995 the presence /absence of $Z$. noltii was noted at stations located using Global Positioning System (GPS) technology ( $N=34,22,90$ stations in 1993, 1994, 1995, respectively). In 1993 and 1994 the stations were randomly placed while in 1995 they were located along transects radiating from the centre of the lagoon.

For each year (1993-1995), the approximate depth limit of the meadow has been delineated as a polygon equidistant between the polygon which connected the deepest stations where $Z$. noltii was present and the polygon which connected the shallowest stations where $Z$. noltii was absent.

\section{6-2003:}

Sampling each summer from 1996 to 2003 was done on a grid of stations 0.33 minute apart (200 stations). The stations were reached as precisely as possible by boat using GPS (accuracy : $100 \mathrm{~m}$ before 1998, 10-20 m after 1998). The exact position of each sampled station was recorded in the field by GPS and these exact coordinates were used for the GIS analysis. At each station, the cover of the species was estimated by scuba divers in 10 quadrats $(50 \times 50 \mathrm{~cm})$ along a transect of about 40 meters. Six classes of cover index were used : 0; <5\%; 5-25\%; 25-50\%; 50-75\%; >75\%. For each species, the frequency of occurrence was defined each year as the ratio of the number of stations were a species was found to the total number of sampled stations.

\subsection{Physical parameters}

\section{Water salinity:}

Since the 1970s water salinity at the centre of the lagoon has been measured monthly using conductivity meter (WTW LP 318). The water salinity during the growing season was defined as the mean salinity calculated from April to September. Salinity was measured using the Practical Salinity Scale.

\section{Suspended sediment concentration:}

Over the 1993-2003 period, 176 water samples were collected at one sampling site (N. 43³2'296; E. $4^{\circ} 38^{\prime} 041$ WGS 84), located 437 meters away from the East shore of the lagoon, to measure the concentration of suspended sediments by filtration. Hourly wind speed data obtained from a meteorological station 12 kilometres from the Vaccarès lagoon, were used to select measurements carried out during calm periods. Only 72 measurements that followed at least 12 hours of low wind (wind speed below $3.5 \mathrm{~m} / \mathrm{s}$ ) were used to investigate the relationship between salinity and suspended sediments.

\section{Bathymetry:}

In 2001, the water depth was measured on 4222 stations along 16 transects (East-West) about $300 \mathrm{~m}$ distant. Along the transects, the distance between two stations was about $130 \mathrm{~m}$ except on the border of the lagoon where the distance was smaller in order to capture the more rapid changes in water depth. 
For each year, hourly wind speeds $(\mathrm{km} / \mathrm{h})$ were pooled in 8 compass sectors of $45^{\circ}$ (North, Northeast, East, etc.) and summed. The sum was defined as the annual distance $(\mathrm{km})$ covered by the wind for each compass sector and the mean annual distance was calculated over the study period. For each station of the sampling grid for vegetation survey, the fetch was measured on a 1/25000 map as the distance from the shoreline along the median of each compass sector $\left(0^{\circ}, 45^{\circ}, 90^{\circ}\right.$, etc). For each station, wave exposure was calculated using a relative (wave) exposure index (REI) modified from Keddy (1982), using the following equation:

$R E I=\sum_{i=1}^{8}\left(D_{i}^{*} F_{i}\right)$

Where: $i=i$ th compass sector, $\mathrm{D}=$ average annual distance covered by wind $(\mathrm{km}), \mathrm{F}=$ fetch $(\mathrm{km})$.

\section{Sediment characteristics:}

In 2003 sediment samples were collected on 23 stations equally distributed on the grid used for the survey of the vegetation. In each station, 3 core samples (diameter $4 \mathrm{~cm}$, depth: $5 \mathrm{~cm}$ ) were collected a few meters apart and mixed. The following sediment characteristics were analysed : grain size composition (\% of clay, fine and coarse silt, and fine and coarse sand), organic matter content, total nitrogen and total phosphorus concentration. In order to reduce the number of variables in the analyses, the correlation matrix of all the variables was calculated. The percentage of fine sediment (clay plus fine silt, $<20 \mu \mathrm{m}$ ) was chosen to describe the sediment.

\subsection{GIS mapping}

The data of the vegetation cover, water depth, REI and percentage of fine sediment were stored as GIS layers in Map-Info ${ }^{T M}$. Grids were generated (using Vertical Mapper ${ }^{\mathrm{TM}}$ ) by interpolation between sampled points, using the triangulation procedure. The slopes were derived from the bathymetry grid. Values of the abiotic factors were assigned to each station where the vegetation was sampled using the resulting grids.

Similarly, the cover data of $Z$. noltii were used to produce maps and calculate the total surface area occupied by the species each year. Because of the lack of vegetation, no interpolation of the cover was made for the other species or for $Z$. noltii in 1997.

\subsection{Statistical analysis}

The non-linear relationship between the salinity and the concentration in suspended sediments was established using the equation $y=\left(a^{*} x\right) /(b+x)$ with an iterative method to search for the least-squares estimates and likelihood confidence limits for the parameters $(p<0.05)$.

Multiple ordinal logistic regressions were built to relate the cover index of $Z$. noltii on sampled stations to depth, REI, slope, and sediment grain size. The cumulative response probabilities were fitted to the logistic distribution function of a linear model using maximum likelihood. Likelihood ratio tests and Akaike's Information Criterion (AIC) were used for choosing the best models. (Johnson and Omland, 2004).

The depth limit was estimated each year by calculating the mean water depth of the 10 deepest stations colonized by each species. One-way ANOVAs were used to test for significant differences in depth limit between years 1996-2003 and means were compared using Tukey-Kramer HSD tests.

Over the period 1996-2003, contingency tables and the likelihood ratio Chi Square tests were used to test if the frequency of occurrence of each species was independent of years. 


\section{Results}

\subsection{Zostera noltii meadow}

Temporal variation in relationship with salinity and suspended sediments

In 1993, the year before the flood, $Z$. noltii occupied almost all the lagoon except the deepest zone at the centre (Fig. 1). Since 1994, the decrease in salinity was followed by a reduction of the total surface area of the meadow (Fig. 1, Fig. 2). In 1996, Z. noltii still occupied $62 \%$ of the lagoon, but the meadow was sparse (Fig. 3). During the winter 1996-1997, the salinity was at its lowest (3.8 in February) and in July 1997, the meadow had disappeared, Z. noltii was restricted to only a few relict sites on the edges. The decrease in salinity was associated with an increased concentration of suspended sediments (Fig. 4). This increase was non-linear with a threshold at a salinity level ca. 5 below which the concentration of suspended sediments drastically increased (Fig. 4).

The increase in salinity during the period 1998-2001, was associated with a progressive recolonization of the lagoon from the shores up to a total surface area similar to 1996 (Fig. 1, Fig. 2). Since 2001, the total surface area of the meadow has been stabilized to ca. $70 \%$ of the surface area of the lagoon while the cover has continued to increase (Fig. 3). No data of suspended sediments was available in 1998, 1999 and 2000. However, since 2001, the concentrations in suspended sediments were low and close to the values measured in 1993 (Fig. 4).

\section{Spatial variation in relationship with depth, slope, exposure index and sediment}

The bathymetry of the lagoon was characterized by shallow depth (max. $2.1 \mathrm{~m}$ ) and gentle slopes up to $2.34 \%$ (Fig. 5a). The steepest slopes were located all around the shores of the lagoon while the centre was almost totally flat, with more of $70 \%$ of the grid points with slope below $0.35 \%$.

The map of the wave exposure index reveals a Northwest - Southeast gradient (Fig. 5b). The Northwest part of the lagoon was more protected than the Southeast part from the dominant wind coming from North-Northwest.

The sediment was rich in fine particles (clay plus fine silt $<20 \mu \mathrm{m}$ ), that varied from $15 \%$ in the south up to $90 \%$ in the north of the lagoon (Fig. 4c). The percent of fine particles was positively correlated with the organic matter content (range: 0.78-4.44\%), the concentration of nitrogen (range: 0.64-2.37 $\%$ ) and of the total phosphorus (range: $413-632 \mathrm{mg} / \mathrm{kg})(r=0.70, r=0.79, r=0.71$ respectively, $n=$ 23).

For each year during the study period (1996-2003), the water depth was the main parameter explaining the spatial variation in Z. noltii cover (Table 1). In 1998 and 1999, when Z. noltii was confined to the shallow borders where the slopes are the steepest (Fig. 1 and Fig. 5a), the best model to explain the cover of $Z$. noltii was a combination of water depth and slope. Since 2000, while the meadow occupied a large part of the lagoon, the REI was the second best explanatory variable after the water depth (Table 1 ). The percent of fine particles in sediment had only a minor effect on $Z$. noltii cover.

\subsection{Plant community dynamics}

\section{Changes in depth limit and frequency of occurrence}

Before 1996, only $Z$. noltii was recorded in the lagoon. However, the small number of sampled stations in 1993, 1994 and 1995 cannot allow us to affirm that the two other angiosperms, $P$. pectinatus and $R$. cirrhosa, and the 2 charophytes species, $C$. galioides and $L$. papulosum were totally absent before 1996.

Over the 1996-2003 period all the species showed significant changes in both their depth limit and their frequency of occurrence (i.e. number of occupied stations / total number of sampled stations) (Table 2). The shallowest depth limit was measured for all the species except C. galioides in 1997 when the salinity was the lowest (Fig. 6). From 1998 until 2001, the increase in salinity was associated with an increase in depth limit and frequency of occurrence for all the species except $C$. galioides (Fig. 6 and Fig.7). Since 2001 the depth limit of $Z$. noltii has not changed while the depth limit and the 
frequency of occurrence of all the other species have decreased except for R. cirrhosa (Fig. 6 and Fig.7).

\section{Discussion}

In the Vaccarès lagoon, salinity fluctuations were associated with consistent changes in the spatial extension and cover of all the macrophyte species. However, after the decrease in water salinity (by 15 to less than 5), the hypothesis of the replacement of the marine species $Z$. noltii by $P$. pectinatus and $R$. cirrhosa was not confirmed. The progressive regression of the $Z$. noltii meadow during the first three years of low salinity was followed by its sudden disappearance in 1997. During the same period the other species remained present at very low frequency of occurrence, confined in shallow water and thus could not be responsible for the decline of $Z$. noltii due to competition. On the other hand, no direct detrimental effect of low salinity on $Z$. noltii could be expected. Z. noltii is known to occur in a large range of salinity conditions, from saline to brackish waters down to a salinity of 7 (Vermaat et al., 2000 for references). Furthermore, in experimental conditions $Z$. noltii showed a maximal germination rate and seedling survival at $1 \%$ salinity, decreasing with higher salinities $(10,20,30$ and 40$)$ (Hootsmans et al., 1987).

We believe that the decline of $Z$. noltii can be explained by the relationship between salinity and the concentration of suspended sediments. In 1997, when the salinity was the lowest, the concentration in suspended solids was about ten times higher than in 1993 when the salinity was the highest. The role of salt in the processes of aggregation and flocculation of suspended solids has been used to explain the sinking of suspended matter in estuaries where freshwater mixes with seawater (Sholkovitz, 1976; Thill et al., 2001; Gustafsson et al., 2000). In the Vaccares lagoon, sediments are frequently resuspended by strong winds. Low salinity might have reduced the settling velocity of suspended solids and resulted in the maintenance of high concentration in suspended sediments. This increase in suspended solids reduced considerably the amount of underwater light available for plants: The vertical light attenuation coefficient (Kd) increased from ca.1 in 1993 to ca. $5 \mathrm{~m}^{-1}$ in 1997 (unpublished data).

Nevertheless, the sudden disappearance of the $Z$. noltii meadow in 1997 contrasted with its ability to maintain itself during the 1994-1996 period while water salinity was already low. At least two explanations can be proposed for this sudden decline. First the relationship between salinity and settling velocity is typically non linear (Sholkovitz, 1976). The lowest salinity reached in 1997 (less than 5) seems to represent a threshold effect of salinity on settling velocity. Such threshold salinities have already been identified in previous studies for fine-grained sediment (Dronkers and Van Leussen, 1988). Second, seagrass meadows are known to trap and anchor sediments and prevent their resuspension by wave actions (Koch, 2001 for references). As a consequence, a "snowball" effect resulting from the synergetic effect of low salinity and spatial reduction of $Z$. noltii meadow, might have exacerbated the meadow regression. The low salinity may have started the snowball effect by increasing water turbidity, resulting in a slight reduction in maximum depth penetration of $Z$. noltii meadow, but which represented a large surface area lost due to the flat morphometry of the lagoon. In turn, the meadow fragmentation would have resulted in the re-suspension of a large amount of sediments, leading to a subsequent increase in turbidity and thus exacerbating meadow regression. Eventually, the high concentration in suspended sediments in the lagoon prevented any species from colonizing deep areas.

The increase in salinity since 1998 allowed a rapid re-colonisation of $Z$. noltii from the shallow borders. The combined positive effects of salinity and the presence of a $Z$. noltii meadow on water transparency may explain the relative increase in depth limit and frequency of occurrence of $R$. cirrhosa and $P$. pectinatus observed in 2001 . In 2003 , ten years after the flood, Z. noltii seemed to have largely recovered from the sudden decrease in water salinity even if the scarcity of the data available before the flood does not allow us to determine if the recovery process of $Z$. noltii has been totally completed. However, while $Z$. noltii was the only angiosperm species recorded in the lagoon before the flood (along with extensive stands of Chaetomorpha linum and Ulva lactuca, unpublished material), four other species still coexisted with $Z$. noltii in 2003. Water salinities around 10-15 seem to be transitional values between a marine and a brackish flora in this lagoon and an unstable species composition can thus be expected.

This study also highlighted the impact of physical factors such as wind-induced waves, slopes and sediment characteristics on the spatial distribution of the meadow. After depth, the relative exposure index was the most important factor determining the spatial variation in $Z$. noltii cover. The negative 
impact of wave action on cover and plant biomass has already been demonstrated for a number of species (Koch, 2001). Furthermore, the negative effect of the steepest slope of the littoral on the cover of $Z$. noltii may also represent a wave effect, although slope certainly represents the combined effects of several factors such as wave actions, sediment structure and stability (Duarte and Kalff, 1988). Finally, the very fine-grained structure of the sediment also negatively influenced the cover of $Z$. noltii in this lagoon. The state of our knowledge on the complex relationship between submerged vegetation and sediment characteristics is still incomplete (Duarte and Kalff, 1988; Koch, 2001), however we suspect that the very fine sediment may prevent pore water exchange with the water column and provide an unstable substrate for the root systems.

\section{Acknowledgements}

We thank Philippe Chauvelon who provided the meteorological data and Martin Plus and Angela Esdaile for helpful suggestions on the manuscript. This study was financially supported by the Programme National de Recherche sur les Zones Humides (Projet: Les Enjeux de la gestion Hydraulique dans le delta du Rhône).

\section{References}

Adams J.B., Knoop W.W. and Bate G.C. 1992. The distribution of estuarine macrophytes in relation to freshwater. Botanica Marina 35, 215-226

Bales M., Moss B., Phillips G., Irvine K. and Stansfield J. 1993. The changing ecosystem of a shallow, brackish lake, Hickling Broad, Norfolk, U.K. II. Long-tem trends in water chemistry and ecology and their implications for restoration of the lake. Freshwater Biology 29: 141-165

Dronkers J. and van Leussen W. 1988. Physical processes in estuaries. Springer Verlag, Berlin

Duarte C.M. 1991. Seagrass depth limits. Aquatic Botany 40: 363-377

Duarte C.M. and Kalff J. 1988. Influence of lake morphometry on the response of submerged macrophytes to sediment fertilization. Canadian Journal of Fisheries and Aquatic Sciences 45: 216-363

Fletcher S.W. and Fletcher W.W. 1995. Factors affecting changes in seagrass distribution and diversity in the Indian River Lagoon complex between 1940 and 1992. Bulletin of Marine Science 57: 49-58

Gustafsson O., Widerlund A., Andersson P.S., Ingri J., Roos P. and Ledin A. 2000. Colloid dynamics and transport of major elements through a boreal river - brackish bay mixing zone. Marine Chemistry 71: 1-21

Heurteaux, P. 1970. Rapports des eaux souterraines avec les sols halomorphes et la vegetation en Camargue. Revue d'Ecologie Terre Vie 4: 47-56 
Hootsmans M.J.M., Vermaat J.E. and Van Vierssen W. 1987. Seed-bank development, germination and early seedling survival of two seagrass species from The Netherlands: Zostera marina L. and Zostera noltii Hornem. Aquatic Botany 28: 275-285

JMP 2000. JMP statistics and graphics guide, version 4. SAS Institute, Cart, NC, USA

Johnson, J.B. and Omland, K.S. 2004. Model selection in ecology and evolution. Trends in Ecology and Evolution 19: 101-108

Kamermans P., Hemminga M.A. and de Jong D.J. 1999. Significance of salinity and silicon levels for growth of a formerly estuarine eelgrass (Zostera marina) population (Lake Grevelingen, The Netherlands). Marine Biology 133: 527-539

Keddy, P.A. 1982. Quantifying within-lake gradients of wave energy: interrelationships of wave energy, substrate particle size and shoreline plants in Axe lake, Ontario. Aquatic Botany 14: 41-58

Kentula M.E. and DeWitt T.H. 2003. Abundance of seagrass (Zostera marina L.) and macroalgae in relation to the salinity-temperature gradient in Yaquina bay, Oregon, USA. Estuaries 26: 11301141

Koch E.W. 2001. Beyond light: Physical, geological, and geochemical parameters as possible submersed aquatic vegetation habitat requirements. Estuaries 24: 1-17

Menéndez M., Hernandez O., Comin F.A. 2002. Spatial Distribution and Ecophysiological Characteristics of Macrophytes in a Mediterranean Coastal Lagoon. Estuarine, Coastal and Shelf Science 55: 403-413

Quammen M.L. and Onuf C.P. 1993. Laguna Madre: Seagrass changes continue decades after salinity reduction. Estuaries 16: 302-310

Sholkovitz E.R.1976. Flocculation of dissolved organic and inorganic matter during the mixing of river water and seawater. Geochimica et Cosmochimica Acta 40: 831-845

Thill A., Moustier S., Garnier J.M., Estournel C., Naudin J.J. and Bottero J.Y. 2001. Evolution of particule size and concentration in the Rhône river mixing zone: influence of salt flocculation. Continental Shelf Research 21: 2127-2140

Vaquer A., Heurteaux P. 1989. Modifications récentes de la végétation aquatique de l'étang du Vaccarès (Camargue, France) liées aux perturbations anthropiques. Annals of Limnology 25 : 25-38 
Vermaat J.E., Verhagen F.C.A. and Lindenburg D. 2000. Contrasting responses in two populations of Zostera noltii Hornem. to experimental photoperiod manipulation at two salinities. Aquatic Botany 67: 179-189

Zieman J.C., Fourqurean J. W. and Frankovich T.A. 1999. Seagrass die-off in Florida Bay: Long-term trends in abundance and growth of Turtle Grass, Thalassia testudinum. Estuaries 22: 460-470

Table 1: Logistic regression models to relate the cover index of $Z$. noltii to depth, relative exposure index (REI), slope and percent of fine sediment. The number of parameters (k), the negative log likelihood, Akaike's Information Criterion (AIC) and $\triangle$ AIC are indicated. Only the best models are presented $(\triangle \mathrm{AIC} \leq 2)$.

\begin{tabular}{|l|l|l|l|l|}
\hline & $\mathrm{k}$ & $-\log \mathrm{L}$ & $\mathrm{AIC}$ & $\Delta \mathrm{AIC}$ \\
\hline 1996 & & & & \\
Depth & 1 & 168.03 & 338.06 & 0.00 \\
Depth + REI & 2 & 167.77 & 339.54 & 1.48 \\
Depth + sediment & 2 & 167.93 & 339.86 & 1.80 \\
Depth + slope & 2 & 168.03 & 340.06 & 2.00 \\
\hline 1998 & & & & \\
Depth + slope & 2 & 101.10 & 206.20 & 0.00 \\
Depth + slope + REI & 3 & 100.90 & 207.80 & 1.60 \\
Depth + slope + sediment & 3 & 101.05 & 208.10 & 1.90 \\
\hline 1999 & & & & \\
Depth + slope & 2 & 174.50 & 353.00 & 0.00 \\
Depth + slope + REI & 3 & 174.20 & 354.40 & 1.40 \\
Depth + slope + sediment & 3 & 174.50 & 355.00 & 2.00 \\
\hline 2000 & & & & \\
Depth + REI + slope & 3 & 165.06 & 336.12 & 0.00 \\
Depth + REI + slope + sediment & 4 & 164.90 & 337.80 & 1.68 \\
\hline 2001 & & & & \\
Depth + REI + slope & 3 & 268.11 & 542.22 & 0.00 \\
Depth + REI + slope + sediment & 4 & 267.30 & 542.60 & 0.38 \\
\hline 2002 & & & & \\
Depth + REI + slope & 3 & 304.15 & 614.30 & 0.00 \\
Depth + REI + slope + sediment & 4 & 304.20 & 616.40 & 2.10 \\
\hline 2003 & & & & \\
Depth & 1 & 293.70 & 589.40 & 0.00 \\
Depth + REI + sediment & 3 & 292.05 & 590.10 & 0.70 \\
Depth + REI & 2 & 293.11 & 590.22 & 0.82 \\
Depth + REI + slope + sediment & 4 & 291.13 & 590.26 & 0.86 \\
Depth + slope & 2 & 293.34 & 590.08 & 1.28 \\
Depth + REI + slope & 3 & 292.49 & 590.98 & 1.58 \\
Depth + sediment & 2 & 293.50 & 591.00 & 1.60 \\
\hline
\end{tabular}


Table 2: Likelihood ratio tests for the frequency of occurrence over the period 1996-2003 and ANOVA's for the mean depth limit.

\begin{tabular}{|l|l|l|l|l|l|}
\hline \multirow{2}{*}{} & \multicolumn{2}{|c|}{ Frequency of occurrence } & \multicolumn{3}{c|}{ Depth limit } \\
\cline { 2 - 6 } & \multicolumn{2}{|c|}{ Likelihood ratio test } & \multicolumn{3}{c|}{ ANOVA } \\
\cline { 2 - 6 } & Chi square & P & Df & F & P \\
\hline Z. noltii & 324.2 & $<0.001$ & 7 & 118.0 & $<0.001$ \\
\hline P. pectinatus & 50.7 & $<0.001$ & 7 & 14.8 & $<0.001$ \\
\hline R. cirrhosa & 59.5 & $<0.001$ & 6 & 24.1 & $<0.001$ \\
\hline L. papulosum & 118.8 & $<0.001$ & 6 & 11.2 & $<0.001$ \\
\hline C. galioides & 71.4 & $<0.001$ & 5 & 2.8 & $<0.05$ \\
\hline
\end{tabular}




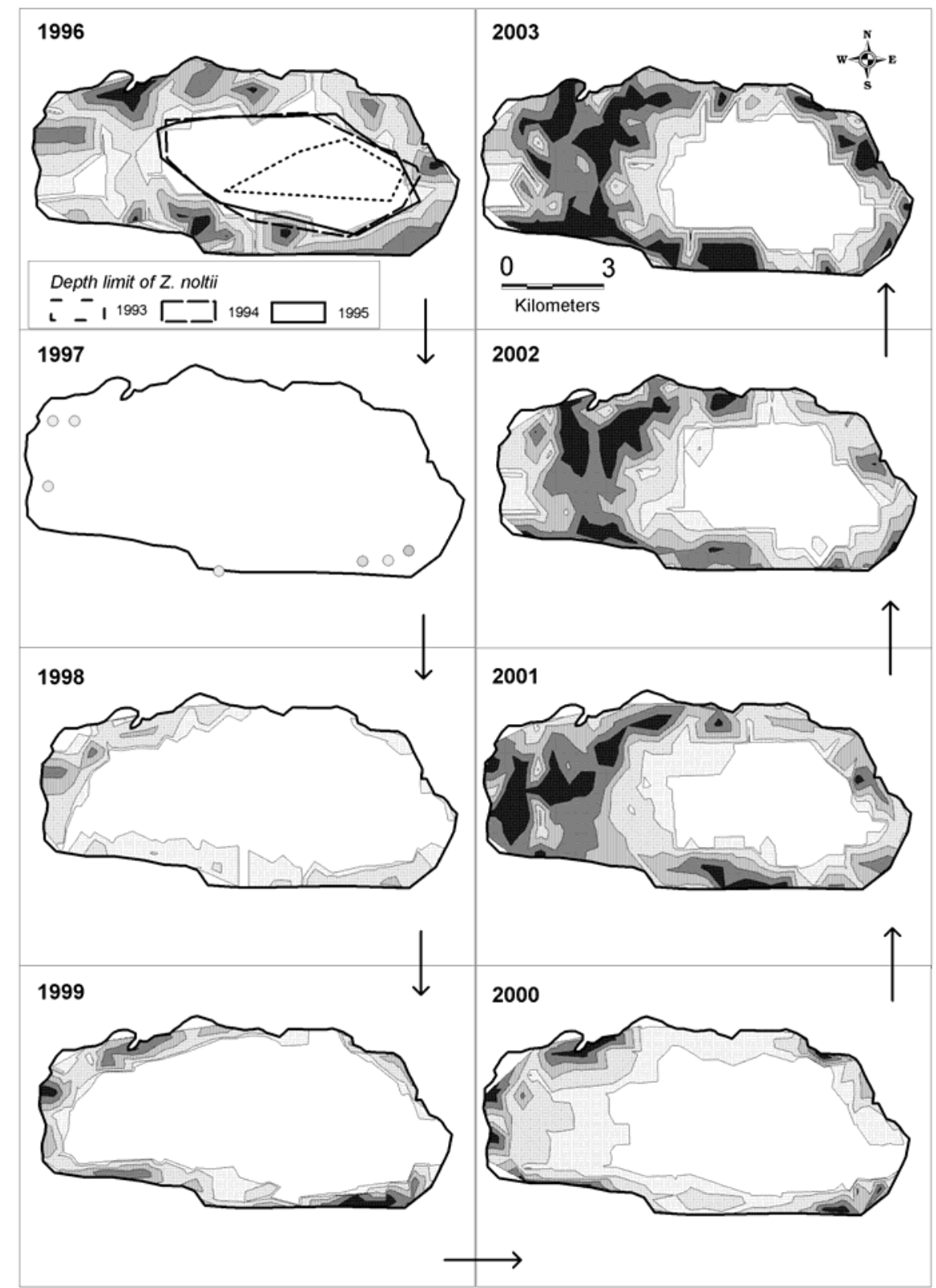

Figure 1: The meadow of $Z$. noltii over the period 1996-2003. The approximate depth limit of the $Z$. noltii meadow in 1993, 1994 and 1995 are indicated by polygons (see methods).

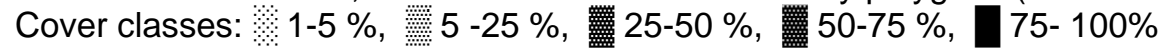




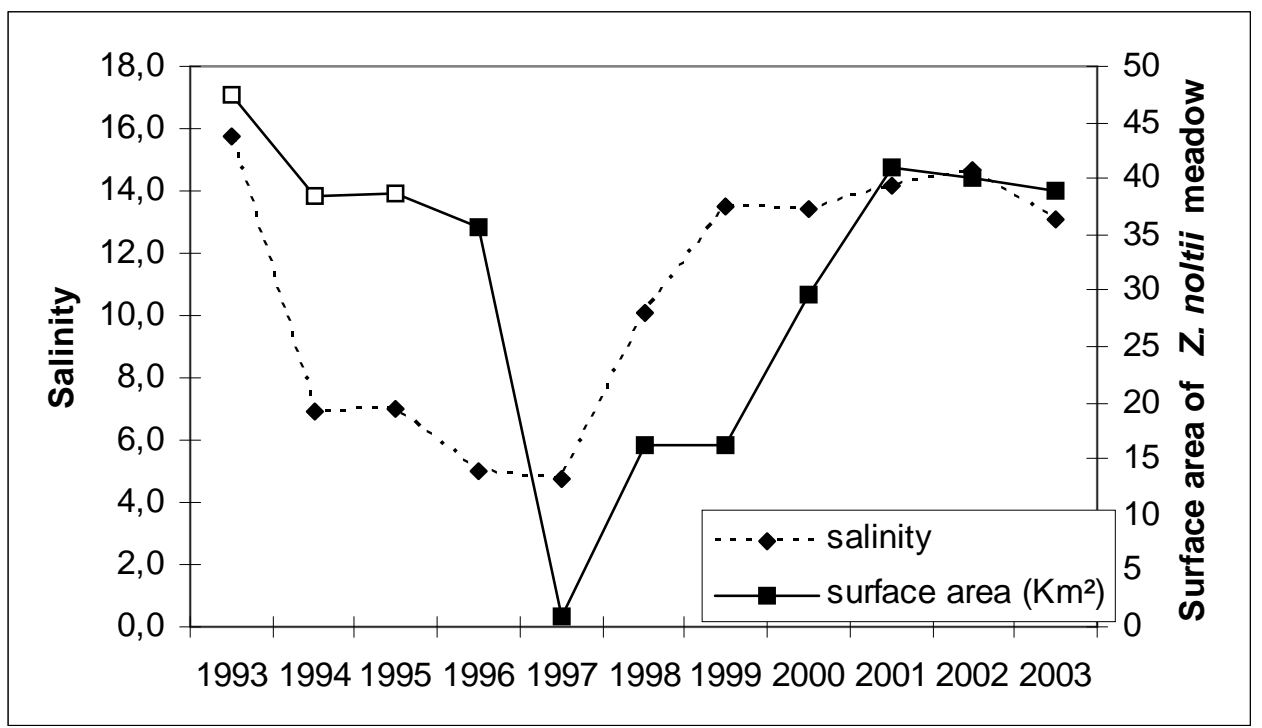

Figure 2: Water salinity during the growing season (mean of the monthly salinity from April to September) and total surface area occupied by the Z. noltii meadow, calculated from the GIS map of cover except in 1993, 1994 and 1995, for which the surface area was estimated using the approximate maximum depth limit polygon (see methods).

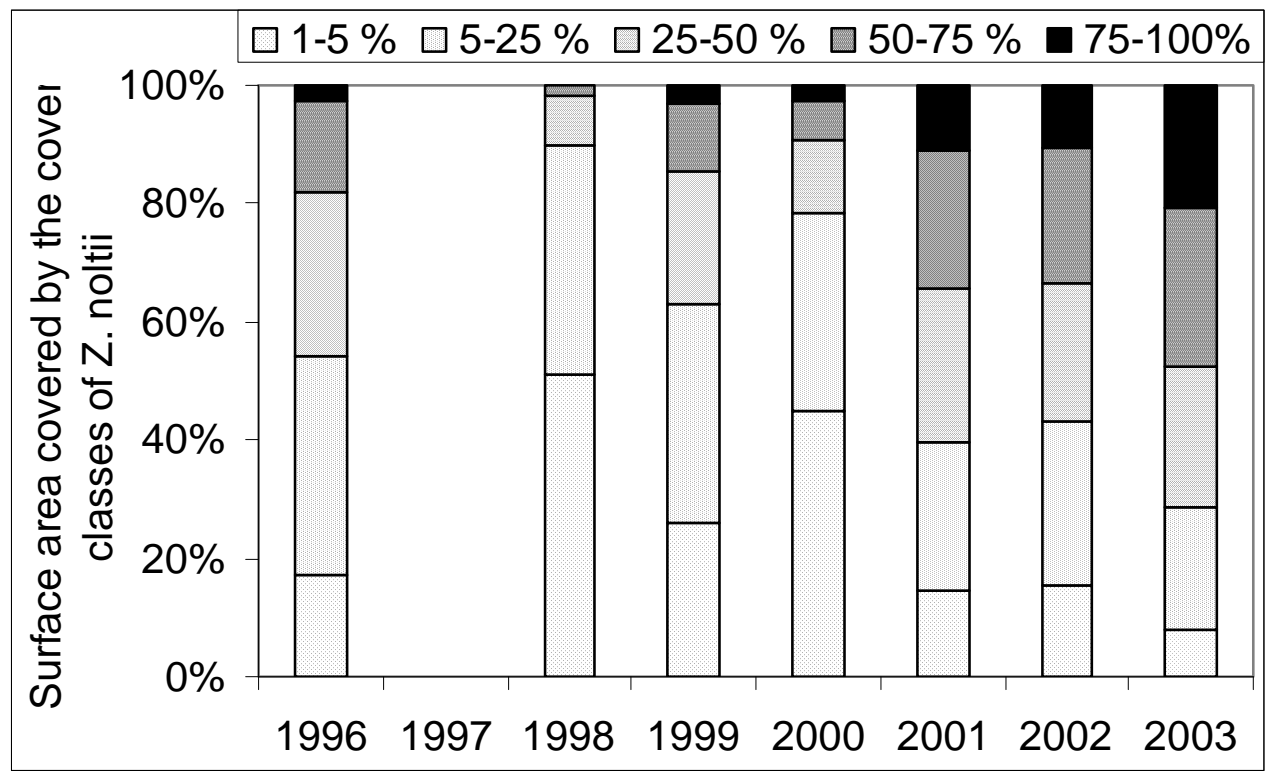

Figure 3 : Percentage of the total surface area of the $Z$. noltii meadow covered by the five classes of cover (see Fig. 1). 


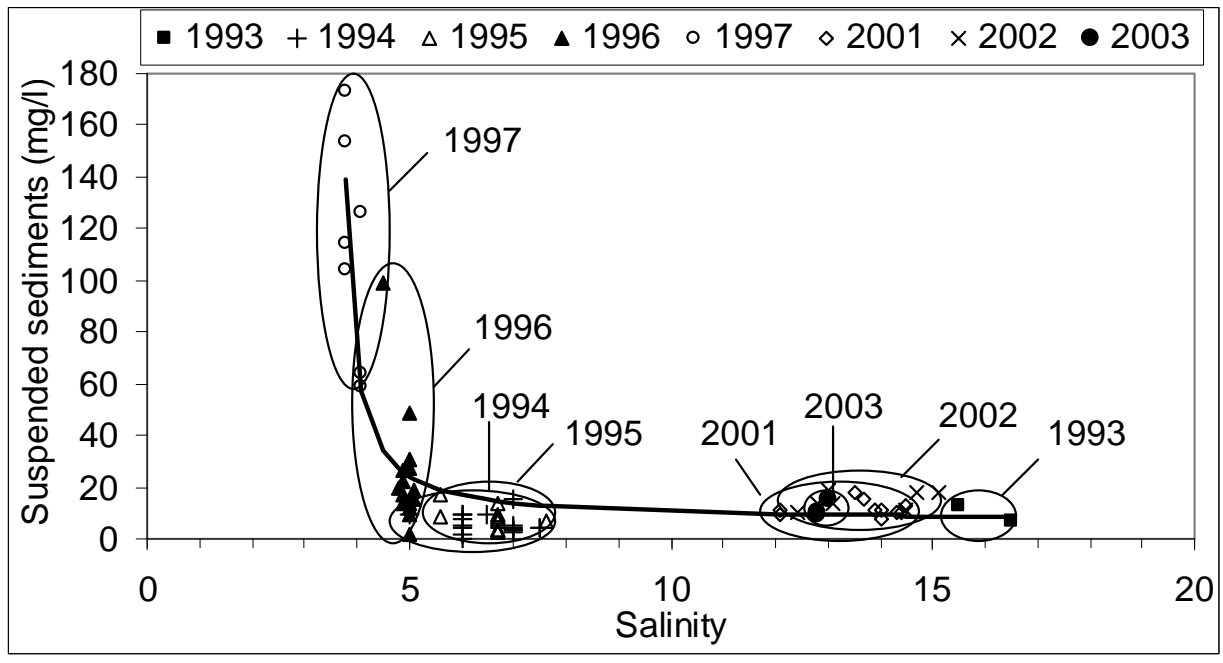

Figure 4: Relationship between salinity and the concentration in suspended sediments during calm days (wind speed $<3.5 \mathrm{~m} / \mathrm{s})$. Fitted equation: $Y=(6.7 * X) /(-3.61+X)$, confidence limits $(p<0.05)$ for parameters: [5.3; 8.2] and [-3.56; -3.66], $\mathrm{n}=72$ days. 


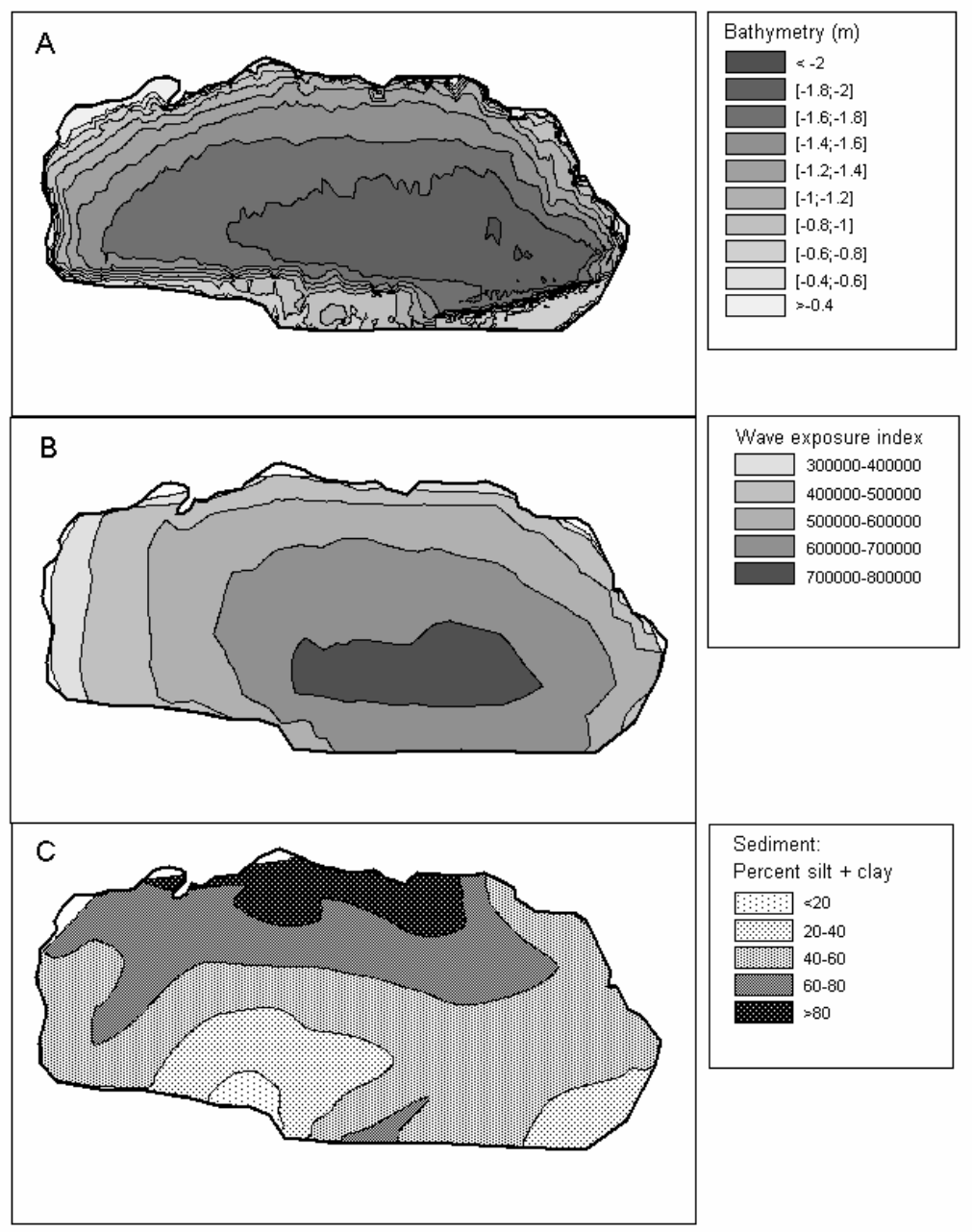

Figure 5: a) Bathymetry b) relative exposure index (REI) and c) percent of fine sediment $(<20 \mu \mathrm{m})$ in the Vaccares lagoon. 

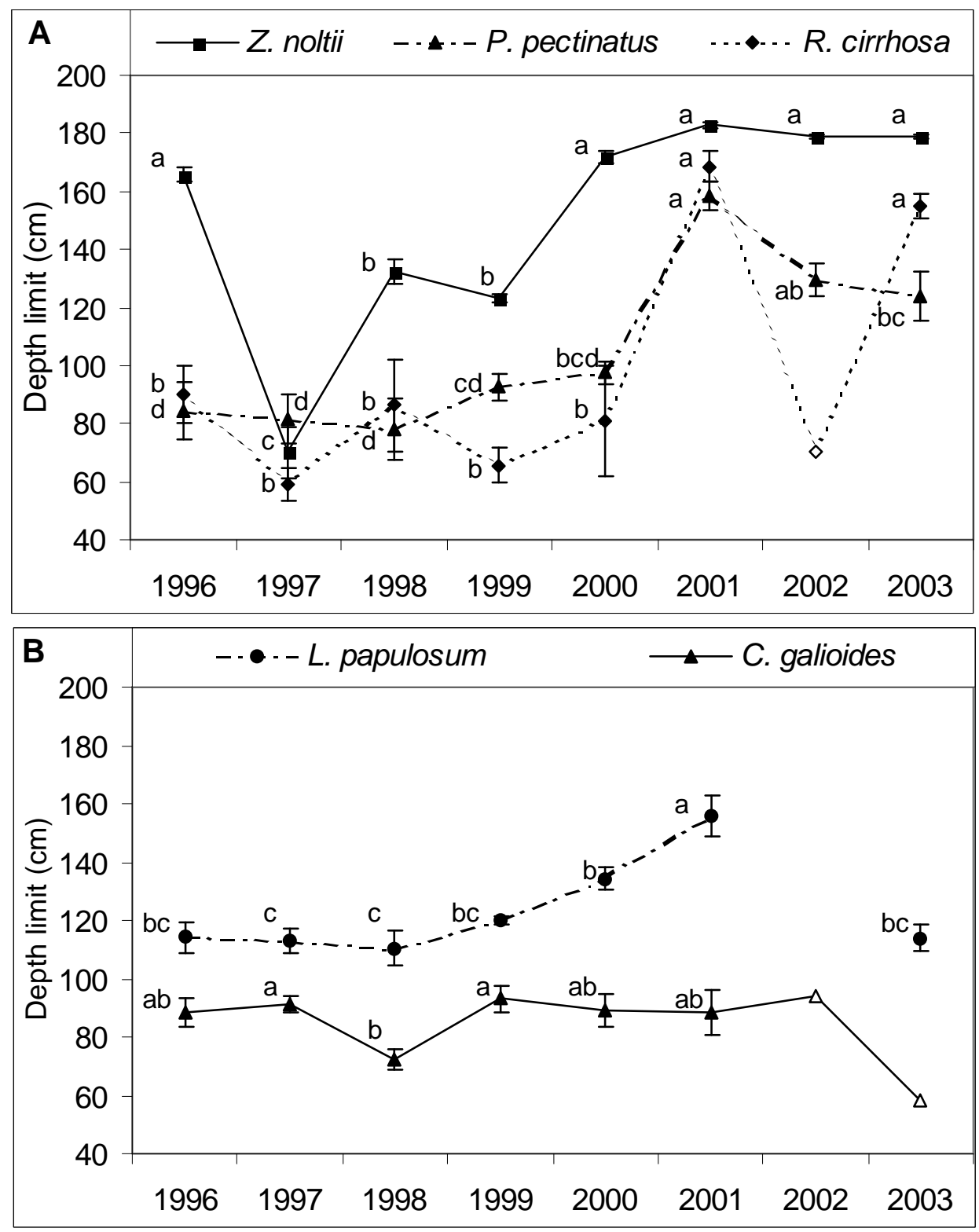

Figure 6: Changes in depth limit for a) the three angiosperms and b) the two charophytes. The depth limit was defined as the mean depth (+/- S.E.) of the 10 deepest stations occupied by each species, except in 2002 and 2003 for $C$. galioides and in 2002 for $R$ cirrhosa and that were present in only one station (open symbols). Means with different letters are significantly different $(p<0.05)$. 

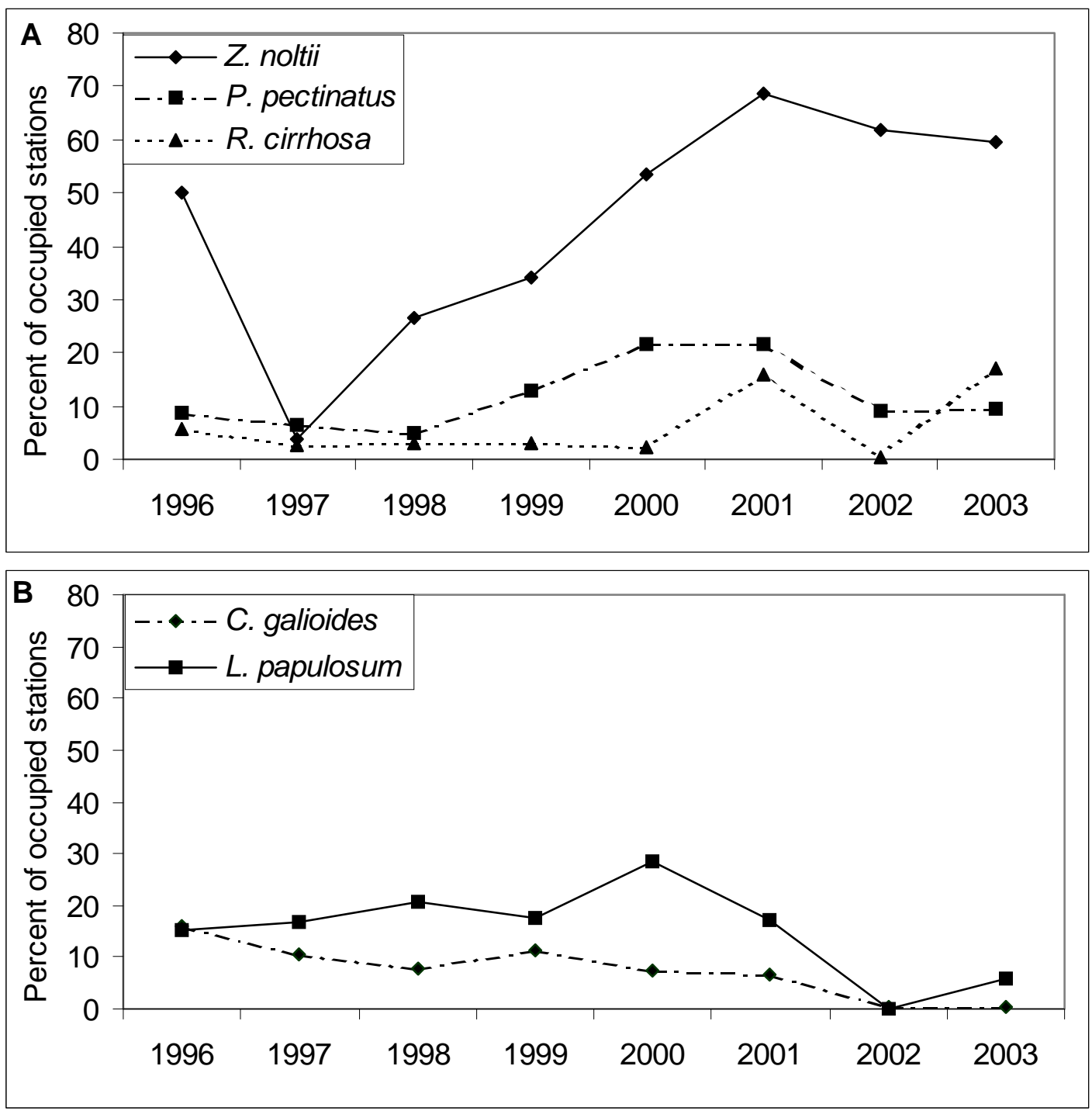

Figure 7: Changes in frequency of occurrence (percent of occupied stations) over the period 19962003 for a) the three angiosperms and b) the two charophytes. 